\title{
İlköğretim Öğrencilerinin Çevre Tutumlarının İncelenmesi
}

\author{
Rasim Önder* \\ Süleyman Demirel Üniversitesi, Eğitim Fakültesi, Isparta
}

\begin{abstract}
$\ddot{O} z$
Çevre geçmişten bize bir miras, geleceğgin emanetidir. Günümüzde artarak devam eden çeore sorunları ciddi şekilde hayatımızı etkiler hale gelmiştir. Sorunlara neden olan insan davranışların belirlemek ve olumlu tutum kazandırmak sorunların çözümü adına ciddi adımlar olarak görülebilir. Bu çalışmanın amacı ilköğretim öğrencilerinin çeore tutumlarının, cinsiyete, oturmuş olduklar evin bahçesinin olup olmadığına, evlerinde evcil hayvan besleyip beslememelerine, okulunda kulüp olup olmamasına ve okulundaki kulüp etkinliklerine katılip katılmamasına, çevre ya da izci kampına katılıp katılmamasına ve fidan dikip dikmemesi gibi değişkenler açısından incelemektir. Tarama modeli kullanılarak yapılan araştırmanın çalışma grubunu 543 sekizinci sını öğrencisi oluşturmaktadır. Veri toplama aracı olarak Atasoy (2005) tarafından geliştirilen Çevre Tutum Ölçeği (ÇTÖ) kullanılmıştır. Veriler 2013-2014 öğretim yılı bahar döneminde toplanmıştır. Verilerin analizinde ilişkisiz örneklemler için t testi kullanılmıştır. Araştırma sonucunda kız öğrencilerin çeore tutumlarının erkek öğrencilere göre daha olumlu olduğu, öğrencilerin bahçeli evde oturmalarn ile bahçesiz evde oturmaları, evcil hayvan beslemeleri ile evcil hayvan beslememelerinin ve okulunda kulüp olması ile okulunda kulüp olmamasının çevre tutum puanlar üzerinde anlaml bir fark oluşturmadığı bulunmuştur. Kulüp etkinliklerine katılan öğrencilerin kulüp etkinliklerine katılmayan öğrencilere göre çevre tutumlarının daha yüksek olduğu, çevre ya da izci kampına katılmalarının çevre tutum puanları üzerinde anlamlı bir farka sebep olmadiğı, fidan diken öğrencilerle fidan dikmeyen öğrencilerin çevreye yönelik tutumları arasında bir fark gözlenmediği sonuçlarına ulaşılmıştır.
\end{abstract}

Anahtar kelimeler: Çevre, Çevresel Tutum, İlköğretim öğrencileri.

\section{Primary School Students' Attitudes towards Environment}

\begin{abstract}
Environment is a heritage from the past and an entrust for the future. Today environmental problems which continue increasingly have effected our lives. To determine the problems that created by humanbeings and to provide positive attitudes towards environmental protection can be seen as serious steps for problem solving. This study aims to examine the attitudes of primary school students towards environment in terms of gender, whether they live in a house with garden or not; they have pets or not, their schools have environmental clubs or not, if they are participated in the club activities or not, if they participate in the environmental or scout camps or not, whether they plant or not. Using the screening model the sample group consisted of 543 eighth grade students. Environmental Attitude Scale (CTO), developed by Atasoy (2005), is used as the data collection tool. Data were collected during the 2013-2014 spring term. In order to analyze the data $t$ test was used. Results show that girls' emvironmental attitudes are more positive compared to boys. However there is no significant difference between the scores of boys and girls towards environment in terms of living in a house with garden or not, having a pet or not, having clubs at school or not. Findings also show that students who participate in club activities have more positive attitudes towards environment compared to students who do not participate in. Students' participation in a scout or environmental camp does not cause a
\end{abstract}


significant difference on environmental attitudes. Besides there is no significant difference between the attitudes of the students who plant and do not plant.

Keywords: Environment, Environmental Attitudes, Primary School students.

\section{Giriş}

Çevre kavramı, çevre sorunlarının artması ve günlük yaşamda kendisini hissettirmesiyle birlikte 20. yy ikinci yarısından itibaren yaygın şekilde kullanılmaktadır. Çevreyi bir kavram olarak değerlendirdiğimizde açık ve yalın bir kavram gibi algılansa da, incelendiğinde, karmaşık ve anlamının çok geniş olduğu görülmektedir (Özdemir, 1997). Çevreyi, canlı varlıkların yaşadığı ortam ile canlıların birbirlerini etkiledikleri ve etkilendikleri alanlar olarak tanımlayabiliriz (Özey, 2001; Güney, 2004). Çevreyi doğal ve yapay çevre olarak da ele almak mümkündür. Doğal çevreyi, insan elinin değmediği bütün varlıklar, yapay çevreyi ise insan eliyle oluşturulan bütün nesneler olarak tanımlanabilir.

İnsanoğlunun doğal çevreyi sınırsız bir kaynak olarak görmesi ve doğal çevrenin vermiş olduğu imkânları gelişigüzel bir şekilde kullanarak telafisi güç olan çevresel sorunlara yol açması günümüzde karşılaştığımız çevre sorunlarının altında yatan nedenlerdendir. Çevre sorunları sadece teknoloji veya yasalarla çözülebilecek bir sorun değildir. Çevre problemlerinin çözümünde bireysel tutum ve değer yargılarının etkisi önem arz etmektedir (Kahyaoğlu, 2009).

Alport'a göre tutum, "bireyin bütün nesnelere karşı göstereceği tepkiler ve durumlar üzerinde yönlendirici veya etkin bir güç oluşturan ve denem bilgilerde organize olan, ussal ve sinirsel bir davranışta bulunmaya hazır olma halidir". Burada tutum, bireyin tepkisini yönlendirici bir unsur olarak onun davranış biçimini belirlemektedir. Tutum kavramı genel olarak bireyin çevresindeki herhangi bir olgu veya nesneye ilişkin sahip olduğu tepki eğilimini ifade eder. Başka bir deyişle tutum, bireyin bir durum, olay ya da olgu karşısında ortaya koyması beklenen olası davranış biçimi olarak tanımlanabilir (İnceoğlu, 2010).

Ortaöğretim kademelerinde bulunan öğrencilerin çevreye yönelik olumlu tutumlar edinmeleri, bunu ileriki hayatlarına taşımaları hem bireysel hem de toplumsal çevre geleceğimiz açısından son derece önemlidir. Yarım asırdan fazla süredir dünya gündemini meşgul eden çevre sorunları ve bu sorunların çözümü, çevreye duyarlı ve olumlu tutum sahibi bireylerle mümkün olacaktır. Böylesine hassas bir konu üzerine etki eden insan davranışlarını olumlu yöne çevirebilmek için şüphesiz, bir eğitim gerekmektedir. Çünkü bireylerin herhangi bir konuya karşı sorumluluklarını geliştirebilmelerinin en etkili yollarından birisi eğitimdir. Yapılan bazı araştırmalarda (Ek ve diğerleri, 2009; Kahyaoğlu ve diğerleri, 2008; Kayalı, 2010) çevre dersinin çevresel tutumu arttırdığı söylemektedir.

Çevre eğitimi bu noktada üstüne düşen görevi üstlenecektir. Ne var ki, çevre eğitimini planlarken davranış bilimlerinin vazgeçilmez unsuru olan tutum ve tutumları etkileyen birey, aile ve çevre değişkenlerinin hangilerinin ya da hangi unsurlarının olumlu tutumlar kazandırmada daha etkili olduğu göz önüne alınmalıdır. 
Tabi ki sosyo-demografik özellikler çevreye yönelik tutumu etkilerken, belki de araştırmalarda değişkenlerimizi çevre ya da yaşamdan seçmek ve doğrudan olumlu tutum geliştirme argümanı olabilecek değişkenleri araştırmak, çevre eğitimini planlama ve bireylerde olumlu tutum geliştirme sürecine doğrudan rehberlik edebilecektir.

Alanyazındaki çalışmalar incelendiğinde (Aslanyolu, 2010; Gökçe ve diğerleri, 2007; Tecer, 2007; Atasoy ve Ertürk, 2008; Yılmaz ve diğerleri, 2004; Sağır ve diğerleri 2004) ilköğretim öğrencilerinin çevreye yönelik tutumlarında problemler olduğu görülmektedir. Araştırma ile Türkiye'de çalışma örnekleri az olan çevre konusuna katkı sağlaması, incelediği değişkenlerin literatürde az olması açısından önemli olup, çalışmanın amacı ilköğretim öğrencilerinin çevreye yönelik tutumlarını farklı değişkenlerle incelemektir. Çalışmanın amacı doğrultusunda aşağıdaki sorulara cevap aranmıştır:

- İlköğretim öğrencilerinin çevre tutum puanları cinsiyetlerine göre anlamlı şekilde farklılaşmakta mıdır?

- İlköğretim öğrencilerinin çevre tutum puanları oturdukları evin bahçe durumuna göre anlamlı şekilde farklılaşmakta mıdır?

- İlköğretim öğrencilerinin çevre tutum puanları evcil hayvan beslemelerine göre anlamlı şekilde farklılaşmakta mıdır?

- İlköğretim öğrencilerinin çevre tutum puanları okulundaki kulüp durumuna göre anlamlı şekilde farklılaşmakta mıdır?

- İlköğretim öğrencilerinin çevre tutum puanları kulüp etkinliklerine katılmasına göre anlamlı şekilde farklılaşmakta mıdır?

- İlköğretim öğrencilerinin çevre tutum puanları çevre ya da izci kampına katılmasına göre anlamlı şekilde farklılaşmakta mıdır?

- İlköğretim öğrencilerinin çevre tutum puanları fidan dikme durumuna göre anlamlı şekilde farklılaşmakta mıdır?

\section{Yöntem}

\subsection{Araştırma Modeli}

$\mathrm{Bu}$ araştırma, betimsel araştırma yöntemlerinden ilişkisel tarama modeli kullanılarak yapılmıştır. Betimsel araştırmalar, verilen bir durumu olabildiğince tam ve dikkatli bir şekilde tanımlayan araştırmalardır (Büyüköztürk ve diğ., 2010). Araştırma, ilköğretim öğrencilerinin farklı değişkenlere göre çevre tutumlarını belirlemeyi amaçladığından tarama modeli kullanılmıştır.

\section{2. Çalışma grubu}

Araştırmanın evrenini 2013-2014 öğretim yılında Isparta'da bulunan ilköğretim öğretim öğrencileri oluşturmaktadır. Araştırmanın örneklemini seçkisiz olmayan örnekleme yöntemlerinden uygun örnekleme yoluyla Isparta'daki Sidre, Hafız, Alaybey, Seçkin, Üç Kardeş, Mavikent ve Atatürk İlköğretim Okulları'nda öğrenim gören 543 tane sekizinci sınıf öğrencisi oluşturmaktadır. 
R. Önder / Karabük Üniversitesi Sosyal Bilimler Enstitüsü Dergisi, 2015, 5 (1), 115-124

Tablo 1: Katılımcllara Ait Betimsel İstatistikler

\begin{tabular}{lccc}
\hline Değişkenler & Kategoriler & $\mathbf{N}$ & $\mathbf{\%}$ \\
\hline Cinsiyet & Kiz & 268 & 49,4 \\
\multirow{3}{*}{ Evde Bahçe Durumu } & Erkek & 273 & 50,3 \\
\cline { 2 - 4 } Evcil Hayvan Besleyen & Olan & 419 & 77,2 \\
& Olmayan & 110 & 20,3 \\
\cline { 2 - 4 } Okulunda Kulüp & Evet & 177 & 32,6 \\
& Hayır & 364 & 67,0 \\
\cline { 2 - 4 } Çevre Etkinliğine & Olan & 341 & 63,4 \\
\multirow{3}{*}{ Çevre ya da İzcilik Kampına } & Olmayan & 189 & 36,6 \\
\cline { 2 - 4 } & Katılan & 327 & 60,2 \\
Şimdiye Kadar Fidan Diken & Katılmayan & 214 & 39,4 \\
\cline { 2 - 4 } & Katılan & 53 & 9,8 \\
\cline { 2 - 4 } & Katılmayan & 488 & 89,9 \\
\cline { 2 - 4 } & Evet & 470 & 86,6 \\
\hline
\end{tabular}

Tablo 1 incelendiğinde araştırmaya katılan sekizinci sınıf öğrencilerinin 268 tanesi k1z öğrenci (\%50,3), 273 tanesi de erkek öğrencidir $(\% 49,4)$. Öğrencilerden 419 tanesinin $(\% 77,2)$ evlerinin bahçeli olduğu,110 öğrencinin $(\% 20,3)$ ise evlerinin bahçeli olmadığ görülmektedir.

Araştırmaya katılan öğrencilerin 177 tanesi $(\% 32,6)$ evlerinde hayvan beslerken, 364 öğrencinin $(\% 67,0)$ ise evlerinde hayvan beslemedikleri, öğrencilerin sayısal olarak $341(\% 63,4)^{\prime} i$ okullarında çevre ile ilgili kulüp olduğunu belirtirken, 189 öğrenci $(\% 37,6)$ ise okullarında çevre ile ilgili herhangi bir kulübün bulunmadığını belirtmişlerdir. Öğrencilerin 327 tanesi $(\% 60,2)$ herhangi bir çevresel etkinliğe katıldıklarını söylerken, 214 tanesi $(\% 39,4)$ ise herhangi bir çevresel etkinliğe katılmadıklarını ifade etmişlerdir. Öğrencilerin 53 tanesi $(\% 9,8)$ çevre kampına ya da izci kampına katıldıklarını söylemiştir. Öğrencilerin 488 tanesi $(\% 89,9)$ ise herhangi bir çevresel kampa ya da izci kampına katılmadıklarını, öğrencilerden 470 tanesi $(\% 86,6)$ şimdiye kadar en az bir adet fidan diktiklerini belirtirken 66 öğrenci $(\% 12,2)$ şimdiye kadar hiç fidan dikmediklerini belirtmiştir.

\subsection{Veri toplama arac1}

Araştırmanın veri toplama aracı Atasoy (2005) tarafından geliştirilen çevre tutum ölçeğidir. İlköğretim öğrencileri için hazırlanmış olan Çevre Tutum Ölçeği (ÇTÖ) ile 6. 7. ve 8. sınıftaki öğrencilerin çevresel duygu, düşünce ve davranışlarının ölçülmesi amaçlanmıştır. ÇTÖ' de toplam 25 madde yer almaktadır. Ölçeğin güvenirliği ile ilgili olarak, ölçeğin Cronbach Alpha değeri 0,85 olarak hesaplanmıştır. $\mathrm{Bu}$ maddeleri okuyan öğrenciler kendi düşünce ve görüşlerini yansıtarak, "kesinlikle katılıyorum", “çoğunlukla katılıyorum”, "kararsızım”, “çoğunlukla katılmıyorum” ve 
"kesinlikle katılmıyorum" seçeneklerinden birini işaretlemişlerdir. Ölçek yapılmadan önce öğrencilerin yapacakları işaretlemelerin doğru veya yanlış olarak değerlendirmeye tabi tutulmayacağ 1 ve her öğrencinin kendi düşünce ve görüşünü içtenlikle yansıtmasının gerekliliği vurgulanmıştır (Atasoy, 2005).

Araştırmada elde edilen verilerin açımlayıcı faktör analizi yapılmışolup Cronbach Alpha katsayısı hesaplanmıştır. Ölçek için hesaplanan Cronbach Alpha katsayısının 0.85 olduğu ve toplam varyansın .56'sını açıklandığı bulunmuştur. Analiz sonucunda hesaplanan KMO değerinin (.91) olması yapılan faktör analizinin çok iyi düzeyde kullanılacağını göstermiştir. Bu durumda ölçeğin güvenilir olduğu söylenebilir (Field, 2009). Barlett testine göre ise bu testin anlamlı olduğunu söylenebilir $(\mathrm{p}<.01)$. Öğrencilerin 25 sorudan oluşan ölçekten alabilecekleri en yüksek puan 125 , en düşük puan ise $25^{\prime}$ tir.

\subsection{Verilerin Toplanması ve Analizi}

Araştırma verileri ilgili okullara gidilerek ölçek aracılığıyla toplanmıştır. İlköğretim öğrencilerinin çevre tutum puanlarının cinsiyet, oturdukları evin bahçeli olup olmaması durumu, evlerinde evcil hayvan besleyip beslememeleri, okulundaki kulüp olup olmaması durumu, okulundaki kulüp etkinliklerine katılıp katılmama durumu, çevre ya da izci kampına en az bir kere katılıp katılmama durumu ve en azından bir kez fidan dikip dikmeme durumu değişkenleriyle ilişkisiz gruplar için $t$ testi analizi yapılmıştır.

\section{Bulgular}

İlköğretim öğrencilerinin çevre tutum puanlarının cinsiyete göre etkisi incelenmiş ve Tablo 5'te gösterilmiştir.

Tablo 5: İlköğretim öğrencilerinin çevre tutum puanlarının cinsiyetlerine göre $\mathrm{t}$ testi sonuçları

\begin{tabular}{lccccc}
\hline Cinsiyet & $\mathbf{N}$ & $\bar{X}$ & $\mathbf{t}$ & sd & $\mathbf{p}$ \\
\hline K1z & 268 & 100,45 & 3,865 & 539 & 0,000 \\
Erkek & 273 & 95,93 & & & \\
\hline
\end{tabular}

Tablo 5 incelendiğinde, kız öğrencilerin çevre tutum puan ortalaması ile ( $\bar{X}=$ $100,45)$ erkek öğrencilerin çevre tutum puanları ortalaması $(\bar{X}=95,93)$ arasında anlamlı bir fark görülmüştür $\left(t_{(539)}=3,865, p<0,01\right)$. Bu durumda k1z öğrencilerin çevre tutumlarının erkek öğrencilere göre daha olumlu olduğu söylenebilir.

İlköğretim öğrencilerinin çevre tutum puanlarının oturdukları evin bahçesinin olup olmaması durumuna ilişkin analizleri yapılmış ve Tablo 6 ' da gösterilmiştir. 
Tablo 6: İlköğretim öğrencilerinin çevre tutum puanlarının oturdukları evin bahçe durumuna ilişkin $t$ testi sonuçları

\begin{tabular}{lccccc}
\hline Bahçe durumu & $\mathbf{N}$ & $\bar{X}$ & $\mathbf{T}$ & $\mathbf{s d}$ & $\mathbf{p}$ \\
\hline Var & 419 & 98,12 & $-0,486$ & 527 & 0,627 \\
Yok & 110 & 98,84 & & & \\
\hline
\end{tabular}

Tablo 6 incelendiğinde, bahçeli evde oturan öğrencilerin çevre tutum puan ortalaması ile $(\bar{X}=98,12)$ bahçesiz evde oturan öğrencilerin çevre tutum puanları ortalaması $(\bar{X}=98,84)$ arasında anlamlı bir fark görülmemiştir $\left(\mathrm{t}_{(527)}=-0,486, \mathrm{p}>0,05\right)$. Diğer bir ifade ile öğrencilerin bahçeli evde oturmaları ile bahçesiz evde oturmaları çevre tutum puanları üzerinde anlamlı bir fark oluşturmamıştır.

İlköğretim öğrencilerinin çevre tutum puanlarının evcil hayvan beslemesine ilişkin analizleri yapılmış ve Tablo 7' de gösterilmiştir.

Tablo 7: İlköğretim öğrencilerinin çevre tutum puanlarının evcil hayvan beslemesine ilişkin $\mathrm{t}$ testi sonuçları

\begin{tabular}{llllll}
\hline Evcil Hayvan Besleme & $\mathbf{N}$ & $\bar{X}$ & $\mathbf{T}$ & sd & $\mathbf{p}$ \\
\hline Evet & 177 & 98,44 & 0,374 & 539 & 0,708 \\
\cline { 2 - 6 } Hayır & 364 & 97,93 & & & \\
\hline
\end{tabular}

Tablo 7 incelendiğinde, evcil hayvan besleyen öğrencilerin çevre tutum puan ortalaması ile $(\bar{X}=98,44)$ erkek öğrencilerin çevre tutum puanları ortalaması ( $\bar{X}$ $=97,93)$ arasında anlamlı bir fark görülmemiştir $\left(t_{(539)}=0,374, p>0,05\right)$. Diğger bir ifade ile öğrencilerin evcil hayvan beslemeleri ile evcil hayvan beslememeleri durumu çevre tutum puanları üzerinde anlamlı bir fark oluşturmamıştır.

İlköğretim öğrencilerinin çevre tutum puanlarının okulundaki kulüp durumuna ilişkin analizleri yapılmış ve Tablo 8'de gösterilmiştir.

Tablo 8: İlköğretim öğrencilerinin çevre tutum puanlarının okulundaki kulüp durumuna ilişkin $\mathrm{t}$ testi sonuçları

\begin{tabular}{lccccc}
\hline Okuldaki Kulüp Durumu & $\mathbf{N}$ & $\bar{X}$ & $\mathbf{t}$ & sd & $\mathbf{p}$ \\
\hline Var & 341 & 98,20 & 0,232 & 528 & 0,816 \\
Yok & 189 & 97,91 & & & \\
\hline
\end{tabular}

Tablo 8 incelendiğinde, evcil hayvan besleyen öğrencilerin çevre tutum puan ortalaması ilen $(\bar{X}=98,20)$ erkek öğrencilerin çevre tutum puanları ortalaması $(\bar{X}$ $=97,91)$ arasında anlamlı bir fark görülmemiştir $\left(t_{(528)}=0,232, p>0,05\right)$. Diğer bir ifade ile öğrencilerin okulunda kulüp olması ile okulunda kulüp olmaması çevre tutum puanları üzerinde anlamlı bir fark oluşturmamıştır.

İlköğretim öğrencilerinin çevre tutum puanlarının kulüp etkinliklerine katılma durumuna ilişkin analizleri yapılmış ve Tablo 9'da gösterilmiştir. 
Tablo 9: İlköğretim öğrencilerinin çevre tutum puanlarının kulüp etkinliklerine katılmasına ilişkin $\mathrm{t}$ testi sonuçları

\begin{tabular}{llllll}
\hline Kulüp Etkinliklerine Katılma & $\mathbf{N}$ & $\bar{X}$ & $\mathbf{t}$ & sd & $\mathbf{p}$ \\
\hline Evet & 327 & 105,12 & 4,202 & 539 & 0,000 \\
Hayır & 214 & 95,09 & & & \\
\hline
\end{tabular}

Tablo 9 incelendiğinde, kulüp etkinliklerine katılan öğrencilerin çevre tutum puan ortalaması ile ( $\bar{X}=105,12)$ kulüp etkinliklerine katılmayan öğrencilerin çevre tutum puanları ortalaması $(\bar{X}=95,09)$ arasında anlamlı bir fark görülmüştür $\left(\mathrm{t}_{(539)}=4,202, \mathrm{p}<0,01\right)$. Kulüp etkinliklerine katılan öğrencilerin kulüp etkinliklerine katılmayan öğrencilere göre çevre tutumlarının daha yüksek olduğu söylenebilir.

İlköğretim öğrencilerinin çevre tutum puanlarının çevre ya da izci kampına katılma durumuna ilişkin analizleri yapılmış ve Tablo 10' da gösterilmiştir.

Tablo 10: İlköğretim öğrencilerinin çevre tutum puanlarının çevre ya da izci kampına katılma ilişkin $\mathrm{t}$ testi sonuçları

\begin{tabular}{llllll}
\hline Çevre ya da İzci Kampına Katılma & $\mathbf{N}$ & $\bar{X}$ & $\mathbf{t}$ & $\mathbf{s d}$ & $\mathbf{p}$ \\
\hline Evet & 327 & 99,56 & 0,763 & 539 & 0,446 \\
\cline { 2 - 6 } Hayır & 214 & 98,04 & & & \\
\hline
\end{tabular}

Tablo 10 incelendiğinde, çevre ya da izci kampına katılan öğrencilerin çevre tutum puan ortalaması ile ( $\bar{X}=99,56)$ çevre ya da izci kampına katılmayan öğrencilerin çevre tutum puanları ortalaması $(\bar{X}=98,04)$ arasında anlamlı bir fark görülmemiştir $\left(\mathrm{t}_{(539)}=0,763, \mathrm{p}>0,05\right)$.

İlköğretim öğrencilerinin çevre tutum puanlarının fidan dikme durumuna ilişkin analizleri yapılmış ve Tablo 11'de gösterilmiştir.

Tablo 11: İlköğretim öğrencilerinin çevre tutum puanlarının fidan dikmeye ilişkin $\mathrm{t}$ testi sonuçları

\begin{tabular}{lccccc}
\hline Fidan Dikme Durumu & $\mathbf{N}$ & $\bar{X}$ & $\mathbf{t}$ & $\mathbf{s d}$ & $\mathbf{p}$ \\
\hline Evet & 322 & 94,02 & 0,662 & 530 & 0,446 \\
Hayır & 210 & 93,14 & & & \\
\hline
\end{tabular}

Tablo 11 incelendiğinde, fidan diken öğrencilerin çevre tutum puanları ortalaması $(\bar{X}=94,02)$ ile fidan dikmeyen öğrencilerin puan ortalaması $(\bar{X}=93,14)$ arasında anlamlı bir fark görülmemiştir $\left(t_{(530)}=0,662, p>0,05\right)$. Diğger bir ifade ile fidan diken öğrencilerle fidan dikmeyen öğrencilerin çevreye yönelik tutumları arasında bir fark gözlenememiştir.

\section{Sonuç ve Öneriler}

İlköğretim öğrencilerinin çevre tutumlarını belirlemek amacıyla yapılan bu çalışmada kız öğrencilerin çevre tutumlarının erkek öğrencilere göre daha olumlu olduğu, kulüp etkinliklerine katılan öğrencilerin kulüp etkinliklerine katılmayan öğrencilere göre çevre tutumlarının daha yüksek olduğu bulunmuştur. Ayrıca 
öğrencilerin bahçeli evde oturmaları ile bahçesiz evde oturmaları çevre tutum puanları üzerinde anlamlı bir fark oluşturmadığı, öğrencilerin evcil hayvan beslemeleri ile evcil hayvan beslememelerinin çevre tutum puanlarında bir farka yol açmadığı, okulunda bir kulüp olması ile okulunda kulüp olmamasının çevre tutum puanları üzerinde anlamlı bir fark oluşturmadığı, çevre ya da izci kampına katılmanın çevre tutum puanları üzerinde anlamlı bir farka sebep olmadığı, fidan diken öğrencilerle fidan dikmeyen öğrencilerin çevreye yönelik tutumları arasında bir fark gözlenmediği sonuçlarına ulaşılmıştır.

Çevre tutumlarının cinsiyete göre değiştiği bulgusu Kostova ve Atasoy'un 2008 yılında yapmış oldukları cinsiyet değişkenin kızlar lehine anlamlı farklılı̆̆ını belirttikleri çalışmayla tutarlılık göstermektedir. Yapılan bazı çalışmalarda bu sonucu desteklemektedir (Paraskevopoulos ve diğerleri 2003;Alp ve diğerleri 2006; Y1lmaz ve diğerleri 2004). Baş (2010), Özpınar (2009), Gökçe ve diğerleri (2007) ve Tecer (2003) çalışmalarında erkek öğrencilerin çevre puanlarının daha yüksek olduğu sonucuna ulaşmışlardır. Araştırma sonuçları Çabuk ve Karacaoğlu (2003) ile Deniş ve Genç (2007) tarafından yapılan çalışmalarla benzerlik göstermektedir. Bu bulgu kız öğrencilerin erkek öğrencilere göre çevreye yönelik daha olumlu tutum sahibi olduklarını göstermiştir. Bu durumun toplumsal nedenlerden kaynaklanabileceği düşünülmektedir. Bunun yanında, kız öğrencilerin doğaya karşı daha ilgili ve duyarlı olması da sonuçların bu şekilde çıkmasını etkileyebilir.

Araştırma bulguları öğrencilerin bahçeli evde oturmaları ile bahçesiz evde oturmaları çevre tutum puanları üzerinde anlamlı bir fark oluşturmadığını göstermiştir. Öğrencilerin evlerinin bahçesinde vakit geçirmemeleri, bahçenin apartman sakinlerine ait ortak bir alan olarak kullanılmasından kaynaklanıyor olabilir. Bunun sebepleri arasında farklı örneklem gruplarıyla çalışılmış olması ya da kullanılan ölçeklerin farklı olması sayılabilir. Bu değişkenin daha detaylı olarak incelenmesi gerekebilir.

İlköğretim öğrencilerinin evcil hayvan beslemeleri ile evcil hayvan beslememelerinin çevre tutum puanlarında anlamlı bir farka yol açmadığı bulgusuna ulaşılmıştır. Fidan diken öğrencilerle fidan dikmeyen öğrencilerin çevreye yönelik tutumları arasındaki farka bakıldığında, aradaki farkın anlamlı olmadığı görülmüştür. Bu durum fidan dikmenin çevre tutumu üzerinde bir etkisi olmadığını göstermektedir.

Araştırmaya katılan öğrencilerin okulunda kulüp olması ile kulüp olmamasının çevre tutum puanları üzerinde anlamlı bir fark oluşturmadığı sonucuna ulaşılmıştır. Bunun başlıca sebebi kulüplerin etkinlik yapmamaları, durağan bir yapıya sahip olmaları olabilir. Araştırmanın diğer alt problemi olan, kulüp etkinliğine katılıp katılmama sonucunda ulaşılan bulgu, kulüp etkinliklerine katılan öğrencilerin kulüp etkinliklerine katılmayan öğrencilere göre çevre tutumlarının daha yüksek olduğunu göstermiştir. Bu sonuç kulüp etkinliklerine katılan öğrencilerin daha olumlu tutumlara sahip olabileceklerini gösterirken, kulüp olduğu halde çevreye yönelik tutumda değişiklik olmamasının sebebi ise kulüplerin etkinlik yapmamaları ya da yapılan etkinlikleri belirli bir öğrenci grubuyla yapmaları olabilir. 
Öğrencilerin araştırma anına kadar, çevre ya da izci kampına katılma veya katılmama durumunun çevre tutumları üzerinde anlamlı bir farka sebep olmadığı bulgusuna ulaşılmıştır. Araştırma sonuçları, Ballantyne ve Packer (2002)' in belirttiği doğa deneyimine dayalı serbest çevre eğitimi uygulamalarının, okul içinde yürütülen formal çevre eğitimi uygulamalarının, öğrencilerin çevrelerini doğru ve gerçekçi şekilde algılamalarında ve sorumlu davranış edinmelerinde boşluğu doldurabilecek bir potansiyele sahip olduğu görüşünü güçlendirmektedir.

Bu sonuçlar doğrultusunda aşağıdaki öneriler geliştirilmiştir;

- İlköğretim okullarındaki kulüplerin daha aktif olması gerektiği ve yapılan etkinlikler farklı öğrenci gruplarıyla yapılabilir,

- Öğrenciler için doğayla iç içe etkinlikler yapılmalı ve doğada nitelikli vakit geçirmeleri sağlanabilir, yaş aralıkları göz önünde alınarak uygulamalı etkinlikler yapılabilir,

- Öğrencilerin sahip oldukları bahçe, evcil hayvan gibi değerlerin doğanın bir parçası olduğu duygusunun benimsetilmesi sonucunda olumlu tutum kazandırılmaya çalışılabilir,

- Çevre farkındalığı kazanmamış bireyler ile çevre sorunlarıyla mücadele etmek mümkün gözükmemektedir. Çevrenin bize geleceğin bir emanet olduğu duygusu kazandırılarak, çevre farkındalığg oluşturulabilir.

\section{Kaynakça}

Alp, E., Ertepınar, H., Tekkaya, C. ve Yılmaz, A. (2008). A survey on Turkish Elementary School Students' Environmental Friendly Behaviors and Associated Variables. Environmental Education Research, 14(2), 129-143.

Arslanyolu, K. (2010). İlköğretim Öğrencilerinin Çevreye Karşı Tutumlarının Çoklu Zekâ Kuramına Göre İncelenmesi. (Basılmamış Yüksek Lisans Tezi). Erzincan: Erzincan Üniversitesi Eğitim Fakültesi.

Atasoy, E. ve Ertürk, H. (2008). İlköğretim Öğrencilerinin Çevresel Tutum ve Çevre Bilgisi Üzerine Bir Alan Araştırması. Erzincan Eğitim Fakültesi Dergisi, 10(1), 105-122.

Ballantyne, R. ve Packer, J. (2002). Nature-Based Excursions: School Students"Perspections of Learning in Natural Environments. International Research in Geographical and Environmental Education, 11(3), 218-231.

Baş Tarsus, M. (2010). Evaluation of Environmental School Students. (Basılmamış Yüksek Lisans Tezi). Ankara: Ortadoğu Teknik Üniversitesi Eğitim Fakültesi.

Çabuk, B. ve Karacaoğlu, Ö. C. (2003). Üniversite Öğrencilerinin Çevre Duyarlılıklarının İncelenmesi. Ankara Üniversitesi Eğitim Bilimleri Fakültesi Dergisi, 36: (1-2), 189-198.

Ek N. H., K1lıç N., Öğdüm P., Düzgün G. (2009). Adnan Menderes Üniversitesi'nin Farklı Akademik Alanlarında Öğrenim Gören İlk ve Son Sınıf Öğrencilerinin Çevre Sorunlarına Yönelik Tutumları ve Duyarlılıkları. Kastamonu Eğitim Dergisi, 17(1).

Gökçe, N., Kaya, E., Aktay, S. ve Özden, M. (2007). İlköğretim Öğrencilerinin Çevreye Yönelik Tutumları. İlköğretim Online E-Dergi, 6(3), 452-468.

Güney, E. (2004). Çevre Sorunları Coğrafyası. Ankara: Gündüz Eğitim ve Yayıncılık. 
İnceoğlu, M. (2010). Tutum Alg̨ İletişim. İstanbul: İyi İşler Yayıncllık ve Matbaacılık

Kahyaoğlu, M., Daban G. ve Yangın S. (2008). İlköğretim Öğretmen Adaylarının Çevreye Yönelik Tutumları. D.Ü. Ziya Gökalp Eğitim Fakültesi Dergisi 11, 42-52.

Kayalı, H. (2010). Sosyal Bilgiler, Türkçe ve Sınıf Öğretmenliği Öğretmen Adaylarının Çevre Sorunlarına Yönelik Tutumları. Marmara Coğrafya Dergisi Sayı: 21, 258-268.

Kostova, Z. ve Atasoy, E. (2008). Methods of Successful Learning in Environmental Education Eğitimde Kuram ve Uygulama, 4(1), 49-78.

Leeming, Frank C. ve Dwyer, William O. (1995). “Children's Enviromental Attitude and Knowledge Scale: Construction and Validation", Journal of Envronmental Education,. 26(3), 458-469.

Özdemir, Ş. (1997). Temel Ekoloji Bilgisi ve Çevre Sorunları. Ankara: Hatiboğlu Yayınları.

Özey, R. (2001). Çevre Sorunları. İstanbul: Aktif Yayınevi.

Özpınar, D. (2009). İlköğretim 4. ve 5. Sınıf Öğrencilerinin Çevre Sorunları Hakkındaki Görüşleri (Afyonkarahisar ili örneği). (Basılmamış Yüksek Lisans Tezi). Afyon: Kocatepe Üniversitesi Eğitim Fakültesi.

Paraskevopoulos, S., Padeliadu, S. ve Zafiropoulos, K. (1998). Environmental Knowledge of Elementary School Students in Greece. Journal of Environmental Education, 29(3):55.

Sağır Ş., Aslan O. ve Cansaran A. (2008). İlköğretim Öğrencilerinin Çevre Bilgisi ve Çevre Tutumlarının Farklı Değişkenler Açısından İncelenmesi. İlköğretim Online E-Dergi, 7(2), 496-511.

Tecer, S. (2007). Çevre İçin Eğitim: Balıkesir İli İlköğretim Öğrencilerinin Çevresel Tutum, Bilgi, Duyarlılık ve Aktif Katılım Düzeylerinin Belirlenmesi Üzerine Bir Çalışma. (Basılmamış Yüksek Lisans Tezi). Zonguldak: Karaelmas Üniversitesi Eğitim Fakültesi.

Yılmaz, Ö., Boone, W.J., ve Andersen, H.O. (2004). Views of Elementary and Middle School Turkish Students Toward Environmental İssues. International Journal of Science Education, 26(12), 1527-1546. 